\title{
O USO DE CÉLULAS-TRONCO MESENQUIMAIS COMO NOVA PERSPECTIVA DE TRATAMENTO PARA HEMOFILIA B
}

\section{THE USE OF MESENCHYMAL STEM CELLS AS A NEW PERSPECTIVE OF TREATMENT FOR HEMOPHILIA B}

\author{
Andrielle de Castilho FERNANDES ${ }^{1,2^{*}}$ \\ Danilo Candido de ALMEIDA ${ }^{1^{*}}$ \\ Lucinei Roberto de OLIVEIRA ${ }^{3}$
}

\begin{abstract}
RESUMO: A Hemofilia B é uma doença genética ligada ao cromossomo X e consiste na deficiência do fator IX (FIX) da coagulação sanguínea. Clinicamente, essa doença é caracterizada por episódios de sangramento principalmente nos músculos, articulações e tecidos moles. O tratamento se dá pela terapia de reposição do FIX derivado do plasma (pdFIX) ou FIX humano recombinante (rhFIX). As inconvenientes infusões intravenosas, juntamente com o alto custo dos pdFIX e/ou rhFIX, incentivaram o desenvolvimento de novas abordagens terapêuticas que permitissem resultados mais estáveis e duradouros. Postulava-se que a terapia gênica, inserção do genes funcional em células e/ou tecidos do paciente, pudesse suprir a necessidade fisiológica do FIX ativo em portador de hemofilia B, contudo as barreiras imunológicas do paciente representaram um grande obstáculo para esta terapia. Logo, os resultados insatisfatórios obtidos com a terapia gênica acrescido da possibilidade de uso terapêutico das células-tronco mesenquimais (CTMs), células consideradas imunoprivilegiadas, direcionou-se as abordagens terapêuticas para a combinação das terapias gênica e celular, ou seja, a manipulação genética de CTMs ex vivo com a finalidade de transplantá-las em hospedeiros, e dessa forma corrigir de forma eficiente e eficaz o fenótipo da hemofilia B. Dessa forma, este artigo revisa as características da hemofilia, os tratamentos disponíveis e as perspectivas para uso de CTMs no tratamento da hemofilia B.
\end{abstract}

Palavras chave: Hemofilia B, Fator IX da coagulação sanguínea, células-tronco mesenquimais

\footnotetext{
${ }^{1}$ Faculdade de Medicina de Ribeirão Preto, Departamento de Clínica Médica;

${ }^{2}$ Universidade de São Paulo; Instituto Nacional de Ciência e Tecnologia em Terapia Celular (INCTC)

3 Universidade Vale do Rio Verde (UNINCOR). E-mail: prof.lucinei.oliveira@ unincor.edu.br

* Mestre em Ciências Médicas - Modalidade Biomédica
} 
ABSTRACT: Hemophilia B is an X-linked bleeding disorder that results from a deficiency in functional coagulation factor IX (hFIX). Clinically, this disease is characterized by bleeding episodes mainly in the soft tissues, joints and muscles. The treatment is given by replacement therapy the plasmaderived FIX (pdFIX) or recombinant human FIX (rhFIX). Annoying intravenous infusions, along with the high cost of pdFIX and / or rhFIX, encouraged the development of new therapeutic approaches that allow more stable and lasting results. It is postulated that the gene therapy, insertion of functional genes into cells and / or tissues of the patient, could meet the physiological need of active FIX in a patient with hemophilia B, but the patient's immunological barriers posed a major obstacle to this therapy. Thus, the unsatisfactory results obtained with gene therapy plus the possibility of therapeutic use of mesenchymal stem cells (MSCs), considered immunoprivileged cells, directed to therapeutic approaches for the combination of gene and cell therapies, in other words, or genetic manipulation of MSCs ex vivo in order to transplant them in hosts, and thus correct efficiently and effectively the phenotype of hemophilia B. Therefore, this article reviews the characteristics of hemophilia, treatments available and the prospects for the use of MSCs in the treatment of hemophilia B.

Keywords: Hemophilia B, Factor IX blood clotting, mesenchymal stem cells

\section{Hemofilia B}

A hemofilia B é uma desordem sanguínea ligada ao cromossomo $\mathrm{X}$ causada pela deficiência quantitativa da proteína Fator IX biologicamente ativa na coagulação sanguínea (Choo et al., 1982; Bithell, 1998). Essa doença é conhecida também como doença de Christmas (Biggs et al., 1952).

Das desordens genéticas a hemofilia é uma das mais comuns, sendo caracterizada clinicamente por episódios de sangramento que podem ocorrer de forma espontânea nas regiões mucocutâneas, tecidos moles e no sistema musculoesquelético. $\mathrm{O}$ sangramento pode ocorrer também em locais potencialmente críticos como, por exemplo, no espaço intracranial ou retroperitoneal (Roberts, 1997).

A hemofilia é classificada de acordo com o nível da proteína Fator IX biologicamente ativa presente no plasma sanguíneo. Dessa maneira, a hemofilia B é classificada nos graus leve, moderado e grave. A forma leve possui níveis acima de $5 \%$ de fator IX ativo circulante, e os pacientes raramente sangram; a moderada apresenta de 1 a $5 \%$ deste fator circulante, e os sangramentos são escassos; por fim, a forma grave da 
doença é definida por quantidades de Fator IX ativo inferiores a $1 \%$, e os pacientes apresentam episódios de sangramento espontâneo nos músculos, articulações e nas mucosas (Lillicrap, 1998; High, 2001).

A hemofilia B afeta um em cada 30 mil homens no mundo. Atualmente, estão cadastrados 1.300 pacientes portadores de hemofilia B no Brasil (Rezende et al., 2005; Fernandes, 2011).

\section{Fator IX da coagulação sanguínea}

O gene do fator IX encontra-se em Xq27.1 (Camerino et al., 1984) e contém 33.5 kilobases, incluindo sete íntrons e oito éxons. O transcrito possui 2.803 bases, composto por uma pequena região 5' UTR de 29 bases, 1.383 bases correspondentes a região codificadora e uma região 3' UTR de 1.390 bases (Choo et al., 1982; Kurachi e Davie, 1982; Anson et al., 1984; Yoshitake et al., 1985; Bowen, 2002) (FIGURA 1A).

A proteína codificada pela seqüência de nucleotídeos do gene do fator IX contém 461 aminoácidos. A proteína Fator IX (FIX) é uma glicoproteína plasmática dependente de vitamina $K$ e sua forma precursora apresenta um peso molecular de $57 \mathrm{kDa}$ (Di Scipio et al., 1978; Taran, 1997), sendo também conhecida como zimogênio (forma inativa, FIX) da família das serino proteases. Nesta forma, é conhecida como proteína precursora e contém o peptídeo sinal de 27 aminoácidos, o qual direciona a proteína para o retículo endoplasmático e em seguida apresenta a seqüência próleader a qual é reconhecida pela enzima $\gamma$-glutamil carboxilase, realizando dessa forma a modificação pós-traducional conhecida como $\gamma$-carboxilação (FIGURA 1 C). Posteriormente, essas duas seqüências peptídicas (pré e própeptídica) são removidas e quatro outras modificações pós-traducionais são realizadas: $\beta$-hidroxilação; glicosilação; sulfatação e fosforilação, antes da proteína ser secretada para a circulação (Furie e Furie, 1995). Em conjunto, essas modificações pós-traduducionais têm a finalidade de proporcionar a proteína FIX dobramentos conformacionais para que ela atinja sua estrutura tridimensional adequada. Nesta etapa a proteína, torna-se apta para ser secretada e desempenhar sua função biológica quando necessária 
(Kaufman, 1998; Lillicrap, 1998; White et al., 1998).

$\mathrm{Na}$ circulação sanguínea a proteína FIX inativa é ativada proteoliticamente via o complexo Fator VIIa/fator tecidual, resultando na forma ativada, a qual é denominada FIXa (Schmidt e Bajaj, 2003). A ativação do FIX ocorre no plasma após a clivagem em duas regiões $\left(\operatorname{Arg}^{145}-\operatorname{Arg}^{146}\right.$ e $\mathrm{Arg}^{180}-\mathrm{Val}^{181}$ ) resultando na formação das cadeias leve (N-terminal de 145 aminoácidos e peso molecular de 16 kDa) e pesada (C-terminal de 234 aminoácidos e peso molecular $29 \mathrm{kDa}$ ) as quais são unidas por uma única ponte dissulfídica entre os resíduos de cisteína 132 e 279 (Schmidt e Bajaj, 2003).

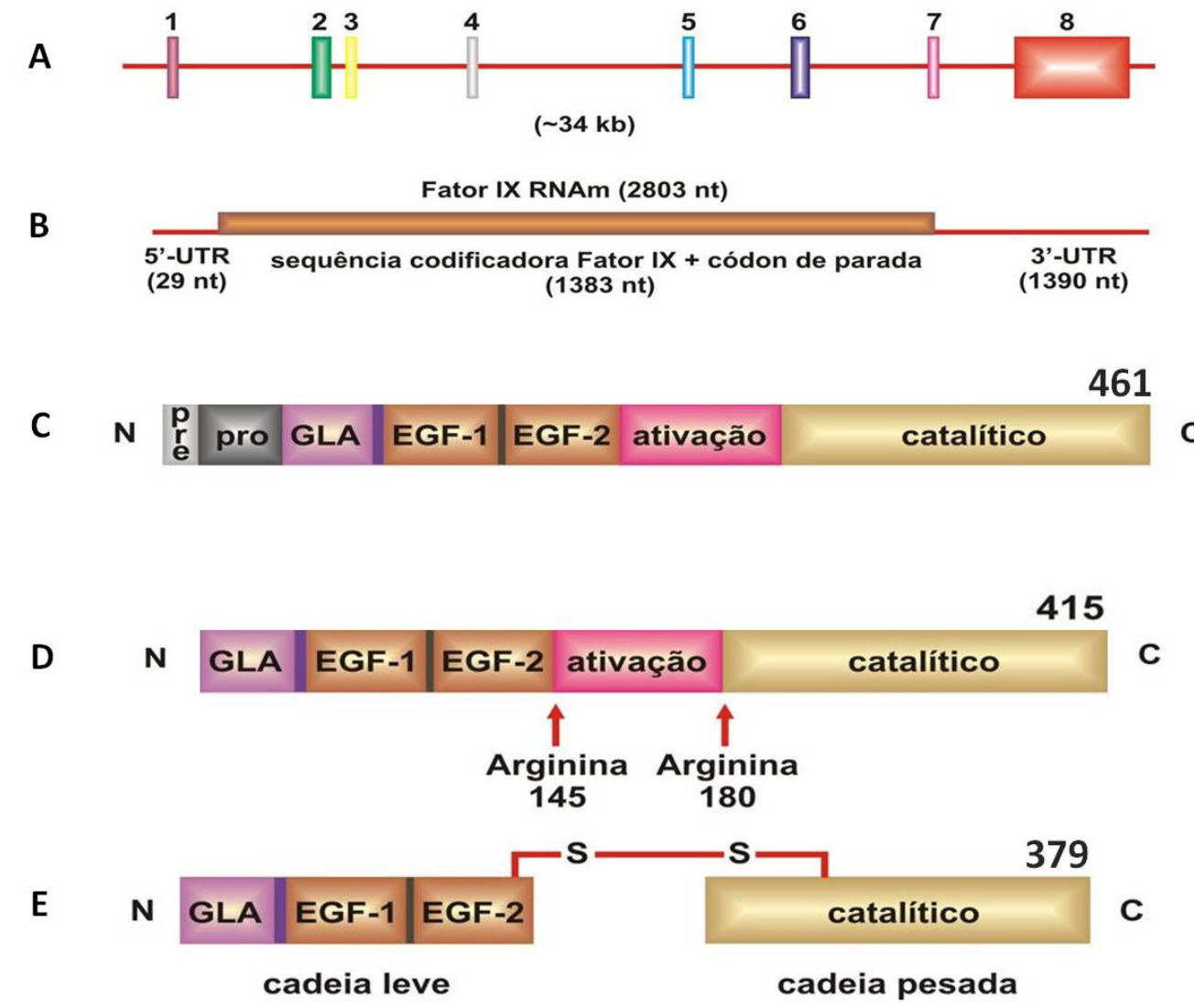

Figura 1 - Gene, RNA mensageiro, Proteína precursora e madura do FIX. (A) Organização genômica do gene fator IX humano, os éxons estão numerados de 1 - 8. (B) RNAm do fator IX mostrando as regiões 5' e 3'UTR e a região codificadora. (C) proteína de Fator IX precursora, compreendendo as sequências PRÉ (peptídio sinal), PRÓ (propetídio), regiões GLA (domínio GLA), EGF (domínios de fator de crescimento epidêrmico), região ativação 
(peptídio de ativação) e catalítico (domínio serino-protease), com um peptídeo de 461 aminoácidos. (D) FIX após a $\gamma$-carboxilação, com 415 aminoáciados. (E) Fator IX ativado composto por 379 aminoacidos, sendo dividido em cadeia leve (N-terminal) e uma cadeia pesada (C-terminal) unidas por uma ponte dissulfídica entre os resíduos de cisteína 132 e 279 (modificado de BOWEN, 2001).

\section{Tratamento atual para hemofilia B}

A mais de uma década a organização americana responsável pelo uso e distribuição de alimentos e medicamentos, a FDA - Food and Drug Administration (Administration), aprovou a comercialização do BeneFIX ${ }^{\mathrm{TM}}$, o único produto constituinte de Fator IX humano recombinante (rhFIX) existente no mercado. Esse produto foi patenteado sob o número US $\quad$ Patent $\quad 5.171 .569$ (<http://www.freepatentsonline.com/>) e é comercializado pela empresa Genetics Institute desde 1997 (Cambridge/Andover, MA) (White et al., 1997; Harrison et al., 1998).

O BeneFIX ${ }^{\mathrm{TM}}$ tem sido considerado a primeira escolha no tratamento da hemofilia B nos países desenvolvidos, principalmente devido a essa molécula recombinante ser altamente purificada, eficaz e comprovadamente segura (Schaub). Entretanto, este produto não é adquirido pelo Brasil e até o momento, o país não apresenta tecnologia suficiente para a produção do rhFIX in house, bem como o fator IX derivado do plasma (dpFIX). No Brasil os produtos derivados do plasma de doadores brasileiros são fracionados por companhias européias e retornam ao país na forma de concentrado de fator liofilizado (dpFIX, Octanine F® - Octapharma), levando a um alto custo e dependência de produtos importados. O Brasil é um dos maiores consumidores mundiais dos fatores concentrados para uso terapêutico e estima-se um gasto anual de US\$ 120 milhões para o tratamento dos pacientes portadores de hemofilia (<http://portal.saude.gov.br/saude>)

(Rezende et al., 2005; Fernandes et al., 2011).

Aliado a este fato, outro problema mundial relacionado ao uso do dpFIX diz respeito à potencial contaminação com agentes virais. Apesar dos avanços biotecnológicos que conduziram ao aprimoramento das metodologias de inativação viral, permitindo formulações mais seguras de 
pdFIX, a possibilidade de contaminação com parvovírus B19, príons infecciosos que causam a nova variante da doença de Creutzfeldt-Jakob (vCJD) e outros vírus emergentes é uma preocupação muito freqüente (Roth, Kessler et al., 2001; Burnouf, 2007).

Dentro desse contexto, a inconveniência das frequentes aplicações intravenosas do FIX (terapia de reposição), juntamente com o alto custo e insegurança dos produtos derivados do plasma, a comunidade científica tem-se incentivado ao desenvolvimento de novas abordagens terapêuticas que permitam resultados mais estáveis e duradouros para o tratamento da hemofilia B (Coutu et al., 2011; Bolton-Maggs, 2006; Lambert et al., 2007).

\section{Terapia Gênica para hemofilia B}

O uso da engenharia genética para a inserção de genes alvos em células e/ou tecidos de um indivíduo para a correção de uma doença; em especial, as hereditárias são chamadas de terapia gênica. A terapia genética visa suprir a necessidade fisiológica de um sistema ou órgão com a adição de genes ou alelos funcionais para correção da patologia (Nathwani, Benjamin et al., 2004; Nathwani, Davidoff et al., 2004).

Nesse sentido, a terapia gênica para hemofilia A e B tem sido alvo de pesquisa há cerca de duas décadas. Diferentes vetores e formas de infusão do mesmo vêm sendo desenvolvidos, mas até o momento não existe um consenso sobre a melhor estratégia terapêutica a ser utilizada (Murphy e High, 2008).

Entre as diferentes construções de cassetes de expressão e os diversos métodos de transferência gênica para a garantia da expressão estável e duradoura dos fatores de coagulação VIII e FIX podemos citar: vetores de expressão não-virais (Jacobs et al., 2008) e virais, tais como os retrovírus (Fernandes et al., 2011), lentivírus (Chen, H. et al., 2006; Picanco et al., 2007), adenovírus (Mccaffrey et al., 2008) e adeno-associados (Nathwani, Benjamin et al., 2004; Nathwani, Davidoff et al., 2004; Wiwanitkit, 2007).

O sistema retroviral baseado no vírus da leucemia de murinos Moleney (MoMuLV) e o sistema lentiviral derivado do vírus da imunodeficiência 
humana - 1 (HIV-1) tem sido considerados sistemas apropriados para a produção do Fator IX recombinante (rFIX), devido a capacidade de se integrarem no genoma do hospedeiro (Park et al., 2000). Além disso, vários modelos experimentais de animais (pequeno, médio e grande porte) portadores de hemofilia $B$ foram desenvolvidos e estão disponíveis para serem utilizados em ensaios pré-clínicos (Murphy e High, 2008).

Nesse contexto, um estudo abordando a administração direta de retrovírus recombinante em animais hemofílicos B, observou uma expressão duradoura do rFVIII superior a 14 meses em camundongos. Entretanto, em cães a expressão do rFIX foi superior a 5 meses. Apesar da expressão prolongada, os níveis terapêuticos dessas proteínas não foram significativamente alcançados (Kay et al., 1993; Vandendriessche et al., 1999).

Tendo como intuito aumentar os níveis de expressão do rFIX in vivo, Xu e colaboradores (Xu et al., 2003; Xu et al., 2007) testaram outra abordagem. Por meio da administração intravenosa do retrovírus recombinante em camundongos recém-nascidos, os autores demonstraram que a expressão sérica do rFIX $(14,3 \mu \mathrm{g} / \mathrm{mL})$ é maior nestes do que em camundongos infectados na fase adulta $(1,75 \mu \mathrm{g} / \mathrm{mL})$. Sugerindo que a alta eficiência de transdução viral ocorre quando o fígado encontra-se em intensa atividade proliferativa, ou seja, logo após o nascimento ou após uma hepatectomia parcial.

Em relação aos seres humanos, cinco diferentes ensaios clínicos de fase I e/ou II foram inicializados entre 1998 and 2001 para o tratamento da hemofilia, os quais utilizaram diferentes sistemas de expressão, incluindo um vetor retroviral, um adenoviral, dois diferentes vetores virais adenoassociated e um não viral. De modo geral, essas abordagens terapêuticas se deparam com a resposta imune do paciente, indicando que as barreiras imunológicas representam um grande obstáculo para alcançar o sucesso da terapia gênica em humanos (Kay et al., 2000; Roth, Tawa et al., 2001; Manno et al., 2003; Powell et al., 2003). Apesar destes desafios, novas estratégias estão sendo exploradas na busca pela combinação ideal do vetor de expressão (viral ou não), método de administração do vetor e a utilização de imunossupressores por períodos 
transitórios para atenuar a resposta imune a entrega do gene. Atualmente existem três ensaios clínicos em andamento cadastrados no ClinicalTrials.gov, banco de testes clínicos realizados no mundo inteiro e mantido pelo ministério da saúde norteamericano, NIH (National Institutes of Health).

Diante de todo o contexto de terapia gênica, observou-se que tanto os vetores virais quanto os não virais quando administrados diretamente no hospedeiro podem gerar resposta imune inata e antiviral específica, o que consequentemente acarreta a redução da meia vida do vetor, além do silenciamento da expressão da proteína exógena e do surgimento de efeitos colaterais indesejáveis (Pfeifer e Verma, 2001).

\section{Células-tronco mesenquimais e terapia celular}

As células-tronco mesenquimais (CTMs) foram identificadas pela primeira vez por Alexander Friedenstein e colaboradores (Friedenstein et al., 1966; 1970; 1974), como células fibroblastóides denominadas de CFU-Fs (colony-forming units-fibroblast) in vitro. Contudo, a denominação de CTMs só foi proposta em 1991 por Arnold Caplan, o qual sugeriu que essas células poderiam ser utilizadas como base para o desenvolvimento de novas tecnologias terapêuticas para a autoreparação celular.

As CTMs humanas já foram isoladas, expandidas in vitro $\mathrm{e}$ caracterizadas a partir de vários tecidos adultos como a medula óssea (Pittenger et al., 1999), membrana e líquido sinovial (De Bari et al., 2001; Jones et al., 2004), músculo (Jiang et al., 2002), sangue de cordão umbilical (Rosada et al., 2003; Lee et al., 2004), sangue periférico (Villaron et al., 2004), polpa do dente (Pierdomenico et al., 2005), veia safena (Covas et al., 2005), periósteo (De Bari et al., 2006), tecido adiposo (Zuk et al., 2001). Essas células também já foram identificadas em tecidos fetais como: veia do cordão umbilical (Covas et al., 2003), pâncreas (Hu et al., 2003), rim (Almeida-Porada et al., 2002), pulmão (Fan et al., 2005), fáscia muscular, fígado, pele, carótida, gônadas, coração, entre outros (Covas et al., 2008). 
Em relação às outras espécies animais, as CTMs já foram isoladas de camundongos (Meirelles Lda e Nardi, 2003), ratos (Inoue et al., 2006), cachorros (Kadiyala et al., 1997), macacos, porcos, ovelhas, cabras coelhos e gatos (Martin et al., 2002). Fato este que demonstra que as CTMs são um tipo conservado de células de mamífero.

Diante destes dados, percebeu-se que as CTMs derivadas dos mais diferentes tecidos e espécies possuíam características fenotípicas e potenciais de diferenciação similares. Contudo, observou-se a existência de algumas diferenças no cultivo, potencial de expansão e marcadores moleculares de superfície celular entre CTMs de origem murina e humana (Minguell et al., 2001; Da Silva Meirelles et al., 2006).

Embora não exista um marcador molecular de superfície celular específico para isolar e identificar as CTMs, Dominici e colaboradores (2006) estabeleceram três critérios mínimos para definir essas células de origem humana (Dominici et al., 2006). Primeiramente, as CTMs devem manter a propriedade de aderência ao plástico quando submetida a uma condição padrão de cultura. Como segunda condição, por citometria de fluxo, as CTMs devem expressar como moléculas de superfície celular CD105, CD73 e CD90, e não devem expressar CD45, CD34, CD14 (ou CD11b), CD79a (ou CD19) e HLA-DR. Por fim, as CTMs devem diferenciar em condroblastos, adipócitos e osteoblastos quando submetidas ao cultivo com indutores específicos de diferenciação in vitro (Dominici et al., 2006).

Em suma, as CTMs diferem das demais células do organismo por possuírem quatro principais características: a) são células indiferenciadas e não especializadas; b) são capazes de multiplicarem por um longo período e permanecerem indiferenciadas (um pequeno número de células pode gerar uma população de células similares); c) sobre estímulo adequado podem ser são capazes de diferenciar em células especializadas de origem mesenquimal; d) possuem atividade trófica para uso terapêutico (Da Silva Meirelles et al., 2009). Acredita-se, que as CTMs dividem-se de forma assimétrica, em outras palavras, uma célula mais progenitora permanece indiferenciada, mantendo o 
pool de células CTMs, enquanto outra célula pode proliferar e se diferenciar em células especializadas com o objetivo de reparo ou repopulação tecidual (Figura 2).

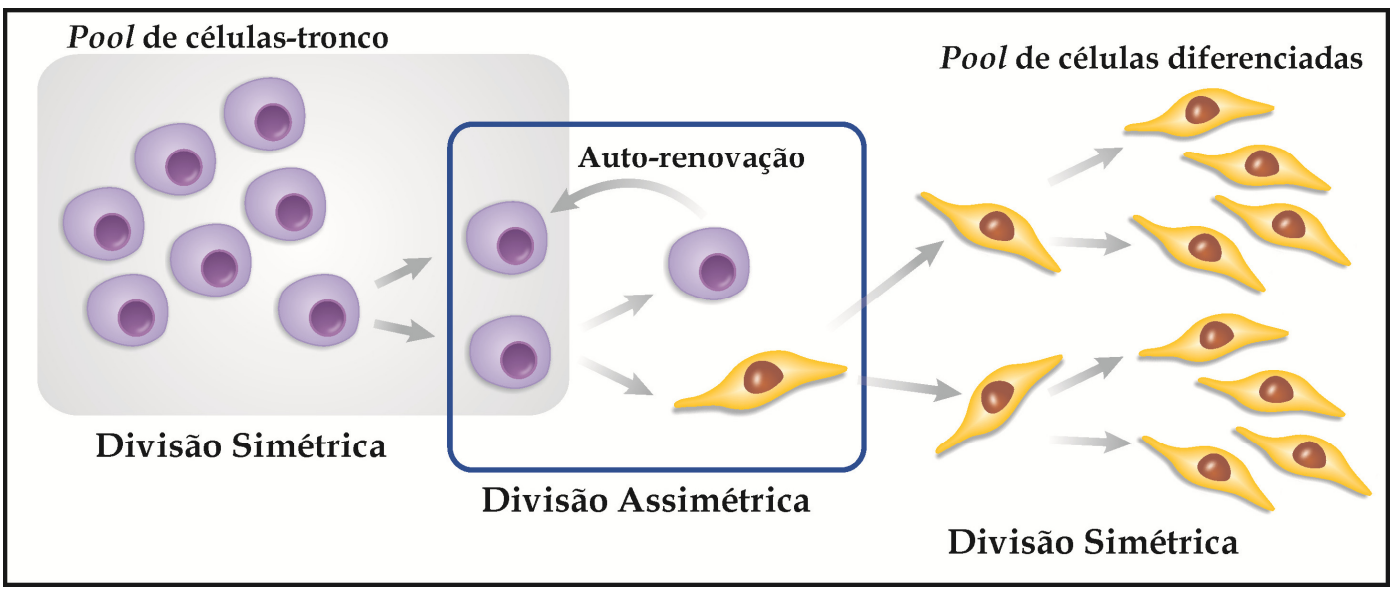

Figura 2 - A auto-renovação é uma característica fundamental das CTMs. Células-tronco podem realizar a divisão simétrica quando necessário para a manutenção do pool de CTMs, e ao mesmo tempo são capazes de dividir de forma assimétrica, originando células diferenciadas. Logo, as células diferenciadas se dividem simetricamente originando um novo tecido especializado.

Devido a facilidade de isolamento, simplicidade de cultivo, rápida expansão, produção de citocinas e extensivo potencial de diferenciação em vários tipos celulares da linhagem mesenquimal, as CTMs estão entre os primeiros tipos de células-tronco a serem introduzidas na clínica com o intuito de explorar o seu potencial terapêutico em diferentes aspectos patológicos (Kassem et al., 2004).

De forma única, a literatura científica considera as CTMs como células imunosupressoras in vitro podendo ser utilizadas como doadoras universais in vivo, sugerindo que as mesmas podem ser enxertadas com sucesso em transplantes alogênicos (Bartholomew et al., 2002; Popp et al., 2009). Djouad F e colaboradores (2003) ao realizar o ensaio de proliferação celular utilizando esplenócitos de camundongos BALB/c, demonstraram que as CTMs murina exibem propriedades imunosupressoras.

Até o momento, as CTMs foram empregadas em estudos pré-clínicos 
destinados para: reconstituição do tendão (Young et al., 1998), distrofia muscular (De Bari et al., 2003), reconstituição óssea (Guillot et al., 2008), reparo de cartilagem articular (Guo et al., 2004), doenças neuronais como Parkinson (Weiss et al., 2006) e trauma de medula espinhal (Akiyama et al., 2002), fibrose pulmonar (Ortiz et al., 2003), doenças renais (Morigi et al., 2004), isquemia periférica (Moon et al., 2006) e lesão cardíaca (Toma et al., 2002).

Outros grupos de pesquisa vem relatando os efeitos positivos da infusão de CTMs em modelos experimentais de lesão hepática induzida. Abdel Aziz e colaboradores (2007) demonstraram a melhora da função hepática em ratos após a infusão sistêmica de CTMs singênicas derivadas da medula óssea. Resultados semelhantes foram obtidos por Zhao et al (2005), os quais infundiram CTMs singênica entre a oitava e décima passagem em ratos submetidos à lesão hepática crônica via infusão de tetracloreto de carbono $\left(\mathrm{CCL}_{4}\right)$. Utilizando camundongos da linhagem NOD/scid tratados com doses letais de $\mathrm{CCL}_{4}$ como modelo experimental, Kuo et al (2008) observou que após a infusão de CTMs humanas houve um significante aumento na taxa de sobrevida dos camundongos. Em conjunto, esses estudos demonstram que os efeitos parácrinos das CTMs podem promover a sobrevida dos hepatócitos endógenos e induziram a proliferação de progenitores hepáticos endógenos.

Quanto aos estudos clínicos de fase I e II, as CTMs foram aplicadas no tratamento para osteogênese imperfeita (Horwitz et al., 1999; 2001; 2002), redução da DECH (doença enxerto contra hospedeiro) (Le Blanc et al., 2004; 2008), reparo de infarto agudo do miocárdio (Chen et al., 2004) e doenças artério-coronarianas (Chen, S. et al., 2006). Em 2011, foi publicado pela primeira vez o uso de Prochymal ${ }^{\mathrm{TM}}$ (Osiris Therapeutics), um tipo de CTMs humanas comercial, para o tratamento de DECH (Prasad et al.). Os resultados deste trabalho foram animadores $\mathrm{e}$ sugeriram que estudos de fase III devem ser realizados em pacientes pediátricos e adultos portadores de DECH.

Atualmente, existem 175 protocolos clínicos cadastrados no banco de dados ClinicalTrial.gov (julho de 2011) que utilizam as CTMs derivadas principalmente do cordão umbilical, medula óssea e tecido 
adiposo. Mas de forma geral, o tratamento para DECH utilizando CTMs humanas é considerado o principal exemplo do potencial terapêutico dessas células.

\section{Terapia celular combinada com a terapia gênica}

Em conjunto com sua ação terapêutica direta, as CTMs também podem ser "unidade produtoras de proteína exógena" para o tratamento de doenças causadas pela síntese de proteínas mutadas e consequentemente inativas, como por exemplo, a hemofilia B. Lembrando que as CTMs possuem maior capacidade proliferativa e meia vida superior as células somáticas, o que as torna células alvo para a terapia gênica.

A terapia gênica combinada com a celular, ou seja, a manipulação gênica de CTMs ex vivo com a finalidade de transplantá-las em hospedeiros, e dessa forma evitar os efeitos colaterais indesejáveis causados pela terapia gênica (Sanz et al.). Além disso, a combinação da terapia gênica e celular pode constituir em um sistema eficiente para a expressão prolongada da proteína de interesse, a qual fica direcionada a um órgão ou tecido específico (Satija et al., 2009).

Neste sentido, alguns pesquisadores vem desenvolvendo estratégias terapêuticas para a produção de várias moléculas anti-câncer, moléculas angiogênicas e proteína sanguíneas como o FVIII e FIX para a correção do fenótipo da hemofilia A e $\mathrm{B}$, respectivamente.

Nos estudos relacionados à produção de moléculas anti-cancer, observou-se que tanto no transplante xenogênico quanto no singênico as CTMs derivadas da medula óssea expressando INF- $\beta$ (Studeny et al., 2002) ou INF- $\alpha$ (Ren et al., 2008) induziram a diminuição da taxa de crescimento tumoral e prolongaram a vida dos camundongos transplantados.

$\begin{array}{ccc}\text { Em } & \text { relação a } & \text { molécula } \\ \text { angiogênica } & \text { VEGF } & \text { (vascular }\end{array}$ endothelial growth factor), Yang $\mathrm{J}$ et al (2007) constatou que a combinação da terapia gênica e celular no transplante singênico de CTMs transfectadas com o cDNA relativo ao VEGF em ratos resultou em melhora na restauração da função cardíaca quando comparado com 
os resultados obtidos com apenas um tipo isolado de terapia.

Quanto as proteínas plasmáticas da coagulação sanguínea, Van Damme e colaboradores (2003) relataram a correção do fenótipo da hemofilia A em camundongos NOD/scid durante três meses após o transplante de CTMs derivadas da medula óssea humana e modificadas geneticamente com vetor retroviral portador do cDNA relativo ao FVIII humano com o domínio B deletado. No mesmo ano, Krebsbach et al (2003) demonstraram após o transplante de CTMs isoladas da medula óssea e modificadas geneticamente com vetor portador do rhFIX a presença de níveis significativos de rhFIX (25 ng/mL) no plasma dos camundongos transplantados por quatro meses. Entretanto, um estudo liderado por Coutu et al (2011) relatou a correção da hemofilia B murina por 11 semanas após a implantação de células CTMs singênicas produtoras de hFIX.

Em conjunto, esses resultados mostram que as CTMs são passíveis de modificação gênica via vetores virais e são capazes de manter a expressão de proteínas exógenas. Portanto, as CTMs possuem uma grande aplicabilidade terapêutica como estratégia para correção de defeitos genéticos in vivo, como a hemofilia $B$, com a vantagem de não causar respostas adversas no paciente.

\section{Referências}

ABDEL AZIZ, M. T. et al. Therapeutic potential of bone marrow-derived mesenchymal stem cells on experimental liver fibrosis. Clin Biochem, v. 40, n. 12, p. 893-9, Aug. 2007.

AKIYAMA, Y.; RADTKE, C.; KOCSIS, J. $D$. Remyelination of the rat spinal cord by transplantation of identified bone marrow stromal cells. J Neurosci, v. 22, n. 15, p. 6623-30, Aug 1. 2002.

ALMEIDA-PORADA, G.; EL SHABRAWY, D.; PORADA, C.; ZANJANI, E. D. Differentiative potential of human metanephric mesenchymal cells. Exp Hematol, v. 30, n. 12, p. 1454-62, Dec. 2002.

ANSON, D. S. et al. The gene structure of human anti-haemophilic factor IX. EMBO J, v. 3, n. 5, p. 1053-60, May. 1984.

BARTHOLOMEW, A. et al. Mesenchymal stem cells suppress lymphocyte proliferation in vitro and prolong skin graft survival in vivo. Exp Hematol, v. 30, n. 1, p. 42-8, Jan. 2002.

BIGGS, R.; DOUGLAS, A. S.; MACFARLANE, R. G.; DACIE, J. V.; PITNEY, W. R.; MERSKEY. Christmas disease: a condition previously mistaken for haemophilia. Br Med J, v. 2, n. 4799, p. 1378-82, Dec 27. 1952. 
BITHELL, T. C. Coagulação Sanguínea. In: LEE, G. R. B., T.C.; FOERSTER, J.; ATHENS, J.W.; LUKENS, J.N. (Ed.). Hematologia Clínica. São Paulo Editora Manole LTDA, 1998. p. 615 - 668.

BOLTON-MAGGS, P. H. Optimal haemophilia care versus the reality. Br J Haematol, v. 132, n. 6, p. 671-82, Mar. 2006.

BOWEN, D. J. Haemophilia A and haemophilia B: molecular insights. Mol Pathol, v. 55, n. 2, p. 127-44, Apr. 2002.

BURNOUF, T. Modern plasma fractionation. Transfus Med Rev, v. 21, n. 2, p. 101-17, Apr. 2007.

CAMERINO, G. et al. Regional localization on the human $\mathrm{X}$ chromosome and polymorphism of the coagulation factor IX gene (hemophilia B locus). Proc Natl Acad Sci U S A, v. 81, n. 2, p. 498-502, Jan. 1984.

CAPLAN, A. I. Mesenchymal stem cells. J Orthop Res, v. 9, n. 5, p. 641-50, Sep. 1991.

CHEN, H.; YAO, H.; HUANG, L.; SHEN, Q.; JIA, W.; XUE, J. Expression of human factor IX gene in murine plasma through lentiviral vector-infected haematopoietic stem cells. Clin Exp Pharmacol Physiol, v. 33, n. 12, p. 1196-201, Dec. 2006.

CHEN, S. et al. Intracoronary transplantation of autologous bone marrow mesenchymal stem cells for ischemic cardiomyopathy due to isolated chronic occluded left anterior descending artery. J Invasive Cardiol, v. 18, n. 11, p. 552-6, Nov. 2006.

CHEN, S. L. et al. Effect on left ventricular function of intracoronary transplantation of autologous bone marrow mesenchymal stem cell in patients with acute myocardial infarction. Am J Cardiol, v. 94, n. 1, p. 925, Jul 1. 2004.
CHOO, K. H.; GOULD, K. G.; REES, D. J.; BROWNLEE, G. G. Molecular cloning of the gene for human anti-haemophilic factor IX. Nature, v. 299, n. 5879, p. 17880, Sep 9. 1982.

COUTU, D. L. et al. Hierarchical scaffold design for mesenchymal stem cell-based gene therapy of hemophilia B.

Biomaterials, v. 32, n. 1, p. 295-305, Jan. 2011.

COVAS, D. T. et al. Multipotent mesenchymal stromal cells obtained from diverse human tissues share functional properties and gene-expression profile with CD146+ perivascular cells and fibroblasts. Exp Hematol, v. 36, n. 5, p. 642-54, May. 2008.

COVAS, D.T., PICCINATO, C.E., ORELLANA, M.D., SIUFI, J.L., SILVA, W.A. JR., PROTO-SIQUEIRA, .R, RIZZATTI, E.G. Mesenchymal stem cells can be obtained from the human saphena vein. Exp Cell Res, v. 309, n. 2, p. 340-4, Oct 1. 2005.

COVAS, D. T.; SIUFI, J. L.; SILVA, A. R.; ORELLANA, M. D. Isolation and culture of umbilical vein mesenchymal stem cells. Braz J Med Biol Res, v. 36, n. 9, p. 117983, Sep. 2003.

DA SILVA MEIRELLES, L.; CHAGASTELLES, P. C.; NARDI, N. B. Mesenchymal stem cells reside in virtually all post-natal organs and tissues. J Cell Sci, v. 119, n. Pt 11, p. 2204-13, Jun 1. 2006.

DA SILVA MEIRELLES, L.; SAND, T. T.; HARMAN, R. J.; LENNON, D. P.; CAPLAN, A. I. MSC frequency correlates with blood vessel density in equine adipose tissue. Tissue Eng Part A, v. 15, n. 2, p. 221-9, Feb. 2009.

DE BARI, C.; DELL'ACCIO, F.; TYLZANOWSKI, P.; LUYTEN, F. P. Multipotent mesenchymal stem cells from adult human synovial membrane. Arthritis Rheum, v. 44, n. 8, p. 1928-42, Aug. 2001. 
DE BARI, C.; DELL'ACCIO, F.; VANDENABEELE, F.; VERMEESCH, J. R.; RAYMACKERS, J. M.; LUYTEN, F. P. Skeletal muscle repair by adult human mesenchymal stem cells from synovial membrane. J Cell Biol, v. 160, n. 6, p. 90918, Mar 17. 2003.

DE BARI, C. et al. Mesenchymal multipotency of adult human periosteal cells demonstrated by single-cell lineage analysis. Arthritis Rheum, v. 54, n. 4, p. 1209-21, Apr. 2006.

DI SCIPIO, R. G.; KURACHI, K.; DAVIE, E. W. Activation of human factor IX (Christmas factor). J Clin Invest, v. 61, n. 6, p. 1528-38, Jun. 1978.

DJOUAD, F. et al. Immunosuppressive effect of mesenchymal stem cells favors tumor growth in allogeneic animals. Blood, v. 102, n. 10, p. 3837-44, Nov 15. 2003.

DOMINICI, M. et al. Minimal criteria for defining multipotent mesenchymal stromal cells. The International Society for Cellular Therapy position statement. Cytotherapy, v. 8, n. 4, p. 315-7, 2006.

FAN, C. G. et al. Characterization and neural differentiation of fetal lung mesenchymal stem cells. Cell Transplant, v. 14, n. 5, p. 311-21, 2005.

FERNANDES, A. C., A.; GONSALES, N.; SWIECH, K.; PICANCO-CASTRO, V.; FACA, S.; COVAS, D. Stable and highlevel production ofrecombinant Factor IX in human hepatic cell line

\section{Biotechnology and Applied}

Biochemistry, p. 1-7, 2011.

FRIEDENSTEIN, A. J.; CHAILAKHJAN, R. K.; LALYKINA, K. S. The development of fibroblast colonies in monolayer cultures of guinea-pig bone marrow and spleen cells. Cell Tissue Kinet, v. 3, n. 4, p. 393403, Oct. 1970.
FRIEDENSTEIN, A. J. et al. Precursors for fibroblasts in different populations of hematopoietic cells as detected by the in vitro colony assay method. Exp Hematol, v. 2, n. 2, p. 83-92, 1974.

FRIEDENSTEIN, A. J.; PIATETZKY, S., II; PETRAKOVA, K. V. Osteogenesis in transplants of bone marrow cells. $\mathbf{J}$

Embryol Exp Morphol, v. 16, n. 3, p. 38190, Dec. 1966.

FURIE, B. C.; FURIE, B. Biosynthesis of factor IX: implications for gene therapy. Thromb Haemost, v. 74, n. 1, p. 274-7, Jul. 1995.

GUILLOT, P. V. et al. Intrauterine transplantation of human fetal mesenchymal stem cells from first-trimester blood repairs bone and reduces fractures in osteogenesis imperfecta mice. Blood, v. 111, n. 3, p. 1717-25, Feb 1. 2008.

GUO, X. et al. Repair of large articular cartilage defects with implants of autologous mesenchymal stem cells seeded into beta-tricalcium phosphate in a sheep model. Tissue Eng, v. 10, n. 11-12, p. 1818-29, Nov-Dec. 2004.

HARRISON, S. et al. The manufacturing process for recombinant factor IX. Semin Hematol, v. 35, n. 2 Suppl 2, p. 4-10, Apr. 1998.

HIGH, K. A. Gene transfer as an approach to treating hemophilia. Circ Res, v. 88 , n. 2, p. 137-44, Feb 2. 2001.

HORWITZ, E.M., GORDON, P.L., KOO, W.K., MARX, J.C., NEEL, M.D., MCNALL, R.Y., MUUL, L., HOFMANN, $\mathrm{T}$. Isolated allogeneic bone marrow-derived mesenchymal cells engraft and stimulate growth in children with osteogenesis imperfecta: Implications for cell therapy of bone. Proc Natl Acad Sci U S A, v. 99, n. 13, p. 8932-7, Jun 25. 2002.

HORWITZ, E.M., PROCKOP, D.J., FITZPATRICK, L.A., KOO, W.W., 
GORDON, P.L., NEEL, M., SUSSMAN, M. et al. Transplantability and therapeutic effects of bone marrow-derived mesenchymal cells in children with osteogenesis imperfecta. Nat Med, v. 5, n. 3, p. 309-13, Mar. 1999.

HORWITZ, E.M., PROCKOP, D.J., GORDON, P.L., KOO, W.W., FITZPATRICK, L.A., NEEL, M.D., MCCARVILLE, M.E. et al. Clinical responses to bone marrow transplantation in children with severe osteogenesis imperfecta. Blood, v. 97, n. 5, p. 1227-31, Mar 1. 2001.

HU, Y. et al. Isolation and identification of mesenchymal stem cells from human fetal pancreas. J Lab Clin Med, v. 141, n. 5, p. 342-9, May. 2003.

INOUE, S. et al. Immunomodulatory effects of mesenchymal stem cells in a rat organ transplant model. Transplantation, v. 81, n. 11, p. 1589-95, Jun 15. 2006.

JACOBS, F. et al. Direct comparison of hepatocyte-specific expression cassettes following adenoviral and nonviral hydrodynamic gene transfer. Gene Ther, v. 15, n. 8, p. 594-603, Apr. 2008.

JIANG, Y.; VAESSEN, B.; LENVIK, T.; BLACKSTAD, M.; REYES, M.; VERFAILLIE, C. M. Multipotent progenitor cells can be isolated from postnatal murine bone marrow, muscle, and brain. Exp Hematol, v. 30, n. 8, p. 896904, Aug. 2002.

JONES, E. A. et al. Enumeration and phenotypic characterization of synovial fluid multipotential mesenchymal progenitor cells in inflammatory and degenerative arthritis. Arthritis Rheum, v. 50, n. 3, p. 817-27, Mar. 2004.

KADIYALA, S.; YOUNG, R. G.; THIEDE, M. A.; BRUDER, S. P. Culture expanded canine mesenchymal stem cells possess osteochondrogenic potential in vivo and in vitro. Cell Transplant, v. 6, n. 2, p. 125-34, Mar-Apr. 1997.

KASSEM, M.; KRISTIANSEN, M.; ABDALLAH, B. M. Mesenchymal stem cells: cell biology and potential use in therapy. Basic Clin Pharmacol Toxicol, v. 95, n. 5, p. 209-14, Nov. 2004.

KAUFMAN, R. J. Post-translational modifications required for coagulation factor secretion and function. Thromb Haemost, v. 79, n. 6, p. 1068-79, Jun. 1998.

KAY, M. A. et al. Evidence for gene transfer and expression of factor IX in haemophilia B patients treated with an AAV vector. Nat Genet, v. 24, n. 3, p. 257 61, Mar. 2000.

KAY, M.A., ROTHENBERG, S., LANDEN, C.N., BELLINGER, D.A., LELAND, F., TOMAN, C., FINEGOLD, $M$. et al In vivo gene therapy of hemophilia B: sustained partial correction in factor IXdeficient dogs. Science, v. 262, n. 5130, p. 117-9, Oct 1. 1993.

KREBSBACH, P. H.; ZHANG, K.; MALIK, A. K.; KURACHI, K. Bone marrow stromal cells as a genetic platform for systemic delivery of therapeutic proteins in vivo: human factor IX model. J Gene Med, v. 5, n. 1, p. 11-7, Jan. 2003.

KUO, T. K. et al. Stem cell therapy for liver disease: parameters governing the success of using bone marrow mesenchymal stem cells. Gastroenterology, v. 134, n. 7, p. 2111-21, 2121 e1-3, Jun. 2008.

KURACHI, K.; DAVIE, E. W. Isolation and characterization of a cDNA coding for human factor IX. Proc Natl Acad Sci U S A, v. 79, n. 21, p. 6461-4, Nov. 1982.

LAMBERT, T. et al. Reformulated BeneFix: efficacy and safety in previously treated patients with moderately severe to severe haemophilia B. Haemophilia, v. 13, n. 3, p. 233-43, May. 2007. 
LE BLANC, K. et al. Mesenchymal stem cells for treatment of steroid-resistant, severe, acute graft-versus-host disease: a phase II study. Lancet, v. 371, n. 9624, p. 1579-86, May 10. 2008.

LE BLANC, K., RASMUSSON, I., SUNDBERG, B., GÖTHERSTRÖM, C., HASSAN, M., UZUNEL, M., RINGDÉN, $O$. Treatment of severe acute graft-versushost disease with third party haploidentical mesenchymal stem cells. Lancet, v. 363, n. 9419, p. 1439-41, May 1. 2004.

LEE, O. K.; KUO, T. K.; CHEN, W. M.; LEE, K. D.; HSIEH, S. L.; CHEN, T. H. Isolation of multipotent mesenchymal stem cells from umbilical cord blood. Blood, v. 103, n. 5, p. 1669-75, Mar 1. 2004.

LILLICRAP, D. The molecular basis of haemophilia B. Haemophilia, v. 4, n. 4, p. 350-7, Jul. 1998.

MANNO, C. S. et al. AAV-mediated factor IX gene transfer to skeletal muscle in patients with severe hemophilia B. Blood, v. 101, n. 8, p. 2963-72, Apr 15. 2003.

MARTIN, D. R.; COX, N. R.; HATHCOCK, T. L.; NIEMEYER, G. P.; BAKER, H. J. Isolation and characterization of multipotential mesenchymal stem cells from feline bone marrow. Exp Hematol, v. 30, n. 8, p. 87986, Aug. 2002.

MCCAFFREY, A. P. et al. The host response to adenovirus, helper-dependent adenovirus, and adeno-associated virus in mouse liver. Mol Ther, v. 16, n. 5, p. 93141, May. 2008.

MEIRELLES LDA, S.; NARDI, N. B. Murine marrow-derived mesenchymal stem cell: isolation, in vitro expansion, and characterization. Br J Haematol, v. 123, n. 4, p. 702-11, Nov. 2003.

MINGUELL, J. J.; ERICES, A.; CONGET, P. Mesenchymal stem cells. Exp Biol Med
(Maywood), v. 226, n. 6, p. 507-20, Jun. 2001.

MOON, M. H. et al. Human adipose tissuederived mesenchymal stem cells improve postnatal neovascularization in a mouse model of hindlimb ischemia. Cell Physiol Biochem, v. 17, n. 5-6, p. 279-90, 2006.

MORIGI, M. et al. Mesenchymal stem cells are renotropic, helping to repair the kidney and improve function in acute renal failure. J Am Soc Nephrol, v. 15, n. 7, p. 1794804, Jul. 2004.

MURPHY, S. L.; HIGH, K. A. Gene therapy for haemophilia. Br J Haematol, v. 140, n. 5, p. 479-87, Mar. 2008.

NATHWANI, A. C.; BENJAMIN, R.; NIENHUIS, A. W.; DAVIDOFF, A. M. Current status and prospects for gene therapy. Vox Sang, v. 87, n. 2, p. 73-81, Aug. 2004.

NATHWANI, A. C.; DAVIDOFF, A. M.; TUDDENHAM, E. G. Prospects for gene therapy of haemophilia. Haemophilia, v. 10, n. 4, p. 309-18, Jul. 2004.

ORTIZ, L. A. et al. Mesenchymal stem cell engraftment in lung is enhanced in response to bleomycin exposure and ameliorates its fibrotic effects. Proc Natl Acad Sci U S A, v. 100, n. 14, p. 8407-11, Jul 8. 2003.

PARK, F.; OHASHI, K.; KAY, M. A. Therapeutic levels of human factor VIII and IX using HIV-1-based lentiviral vectors in mouse liver. Blood, v. 96, n. 3, p. 1173-6, Aug 1. 2000.

PFEIFER, A.; VERMA, I. M. Gene therapy: promises and problems. Annu Rev Genomics Hum Genet, v. 2, p. 177-211, 2001.

PICANCO, V. et al. Recombinant expression of coagulation factor VIII in hepatic and non-hepatic cell lines stably transduced with third generation lentiviral vectors comprising the minimal factor VIII 
promoter. Cytotherapy, v. 9, n. 8, p. 78594, 2007.

PIERDOMENICO, L. et al. Multipotent mesenchymal stem cells with immunosuppressive activity can be easily isolated from dental pulp.

Transplantation, v. 80 , n. 6, p. 836-42, Sep 27. 2005.

PITTENGER, M. F. et al. Multilineage potential of adult human mesenchymal stem cells. Science, v. 284, n. 5411, p. 143-7, Apr 2. 1999.

POPP, F. C. et al. Mesenchymal stem cells can affect solid organ allograft survival. Transplantation, v. 87, n. 9 Suppl, p. S5762, May 15. 2009.

POWELL, J. S. et al. Phase 1 trial of FVIII gene transfer for severe hemophilia A using a retroviral construct administered by peripheral intravenous infusion. Blood, v. 102, n. 6, p. 2038-45, Sep 15. 2003.

PRASAD, V. K. et al. Efficacy and safety of ex vivo cultured adult human mesenchymal stem cells (Prochymal) in pediatric patients with severe refractory acute graft-versus-host disease in a compassionate use study. Biol Blood Marrow Transplant, v. 17, n. 4, p. 534-41, Apr.

REN, C.; KUMAR, S.; CHANDA, D.; CHEN, J.; MOUNTZ, J. D.; PONNAZHAGAN, S. Therapeutic potential of mesenchymal stem cells producing interferon-alpha in a mouse melanoma lung metastasis model. Stem Cells, v. 26, n. 9, p. 2332-8, Sep. 2008.

REZENDE, S. M.; PIMENTEL, B. D.; ARAUJO, J. P. Knocking down the price of factor concentrates in Brazil. Haemophilia, v. 11, n. 3, p. 290-1, May. 2005.

ROBERTS, H. R. L. D. K. The molecular biology of hemophilia $\mathrm{B}$

In: MEDICAL, C. H. (Ed.). Hemophilia, 1997. p. 35-50.
ROSADA, C.; JUSTESEN, J.; MELSVIK, D.; EBBESEN, P.; KASSEM, M. The human umbilical cord blood: a potential source for osteoblast progenitor cells. Calcif Tissue Int, v. 72, n. 2, p. 135-42, Feb. 2003.

ROTH, D. A.; KESSLER, C. M.; PASI, K. J.; RUP, B.; COURTER, S. G.; TUBRIDY, K. L. Human recombinant factor IX: safety and efficacy studies in hemophilia B patients previously treated with plasmaderived factor IX concentrates. Blood, v. 98, n. 13, p. 3600-6, Dec 15. 2001.

ROTH, D. A.; TAWA, N. E., JR.; O'BRIEN, J. M.; TRECO, D. A.; SELDEN, R. F. Nonviral transfer of the gene encoding coagulation factor VIII in patients with severe hemophilia A. N Engl J Med, v. 344, n. 23, p. 1735-42, Jun 7. 2001.

SANZ, L.; COMPTE, M.; GUIJARROMUNOZ, I.; ALVAREZ-VALLINA, L. Non-hematopoietic stem cells as factories for in vivo therapeutic protein production. Gene Ther, May 12.

SATIJA, N. K. et al. Mesenchymal stem cell-based therapy: a new paradigm in regenerative medicine. J Cell Mol Med, v. 13, n. 11-12, p. 4385-402, Nov-Dec. 2009.

SCHAUB, R. G. Recent advances in the development of coagulation factors and procoagulants for the treatment of hemophilia. Biochem Pharmacol, v. 82, n. 2, p. 91-8, Jul 15.

SCHMIDT, A. E.; BAJAJ, S. P. Structurefunction relationships in factor IX and factor IXa. Trends Cardiovasc Med, v. 13, n. 1, p. 39-45, Jan. 2003.

STUDENY, M.; MARINI, F. C.; CHAMPLIN, R. E.; ZOMPETTA, C.; FIDLER, I. J.; ANDREEFF, M. Bone marrow-derived mesenchymal stem cells as vehicles for interferon-beta delivery into tumors. Cancer Res, v. 62, n. 13, p. 36038, Jul 1. 2002. 
TARAN, L. D. Factor IX of the blood coagulation system: a review.

Biochemistry (Mosc), v. 62, n. 7, p. 68593, Jul. 1997.

TOMA, C.; PITTENGER, M. F.; CAHILL, K. S.; BYRNE, B. J.; KESSLER, P. D. Human mesenchymal stem cells differentiate to a cardiomyocyte phenotype in the adult murine heart. Circulation, v. 105, n. 1, p. 93-8, Jan 1. 2002.

VAN DAMME, A. et al. Bone marrow mesenchymal cells for haemophilia A gene therapy using retroviral vectors with modified long-terminal repeats.

Haemophilia, v. 9, n. 1, p. 94-103, Jan. 2003.

VANDENDRIESSCHE, T. et al. Longterm expression of human coagulation factor VIII and correction of hemophilia A after in vivo retroviral gene transfer in factor VIII-deficient mice. Proc Natl Acad Sci U S A, v. 96, n. 18, p. 10379-84, Aug 31. 1999.

VILLARON, E. M. et al. Mesenchymal stem cells are present in peripheral blood and can engraft after allogeneic hematopoietic stem cell transplantation. Haematologica, v. 89, n. 12, p. 1421-7, Dec. 2004.

WEISS, M. L. et al. Human umbilical cord matrix stem cells: preliminary characterization and effect of transplantation in a rodent model of Parkinson's disease. Stem Cells, v. 24, n. 3, p. 781-92, Mar. 2006.

WHITE, G. et al. Clinical evaluation of recombinant factor IX. Semin Hematol, v. 35, n. 2 Suppl 2, p. 33-8, Apr. 1998.

WHITE, G. C., 2ND; BEEBE, A.; NIELSEN, B. Recombinant factor IX. Thromb Haemost, v. 78, n. 1, p. 261-5, Jul. 1997.
WIWANITKIT, V. Functions of AAVCMV-F.IX And AAV-EF1alpha-F.IX in gene therapy for hemophilia B. Hum Gene Ther, v. 18, n. 2, p. 89-92, Feb. 2007.

XU, L. et al. Neonatal or hepatocyte growth factor-potentiated adult gene therapy with a retroviral vector results in therapeutic levels of canine factor IX for hemophilia B.

Blood, v. 101, n. 10, p. 3924-32, May 15. 2003.

XU, L., MEI, M., HASKINS, M.E., NICHOLS, T.C., O'DONNELL, P., CULLEN, K., DILLOW, A. et al Immune response after neonatal transfer of a human factor IX-expressing retroviral vector in dogs, cats, and mice. Thromb Res, v. 120, n. 2, p. 269-80, 2007.

YANG, J. et al. Effects of myocardial transplantation of marrow mesenchymal stem cells transfected with vascular endothelial growth factor for the improvement of heart function and angiogenesis after myocardial infarction. Cardiology, v. 107, n. 1, p. 17-29, 2007.

YOSHITAKE, S.; SCHACH, B. G.; FOSTER, D. C.; DAVIE, E. W.; KURACHI, K. Nucleotide sequence of the gene for human factor IX (antihemophilic factor B). Biochemistry, v. 24, n. 14, p. 3736-50, Jul 2. 1985.

YOUNG, R. G.; BUTLER, D. L.; WEBER, W.; CAPLAN, A. I.; GORDON, S. L.;

FINK, D. J. Use of mesenchymal stem cells in a collagen matrix for Achilles tendon repair. J Orthop Res, v. 16, n. 4, p. 406-13, Jul. 1998.

ZHAO, D. C. et al. Bone marrow-derived mesenchymal stem cells protect against experimental liver fibrosis in rats. World J Gastroenterol, v. 11, n. 22, p. 3431-40, Jun 14. 2005.

ZUK, P. A. et al. Multilineage cells from human adipose tissue: implications for cellbased therapies. Tissue Eng, v. 7, n. 2, p. 211-28, Apr. 2001. 